\title{
Utilization of the infrared thermography to identify the convective heat transfer coefficient into a rotating cylinder with an axial airflow.
}

\author{
by S. Seghir-Ouali, ${ }^{* * * *}$, D. Saury , S. Harmand ${ }^{* * * *}$, O. Phillipart", D. Laloy ${ }^{* * * * *}$ \\ Laboratoire de Mécanique et Energétique Université de Valenciennes et du Hainaut- \\ Cambrésis, Le Mont Houy, F-59313 Valenciennes CEDEX 9, France \\ ** AREVA NP, BP 189, F-59573 Jeumont, France \\ Centre National de Recherche Technologique - FUTURELEC 2
}

\begin{abstract}
This article presents an experimental technique to identify the convective heat transfer coefficient inside an empty rotating cylinder with an inner axial airflow. This method is based on infrared thermography and consists in heating the outer face of the rotating cylinder using infrared lamps and acquiring the evolution of the external surface temperature versus time using an infrared camera. Heat transfer coefficients are then identified via three specific methods (an inverse model, a thermally thin wall model and an analytical method). The experiments were carried out for numerous rotational speeds and inner airflow rates.
\end{abstract}

\section{Introduction}

Since the electric motors beginning and the will to increase their performances, such machines are confronted to heating problems. Some parts of these machines can reach significant and disallowed temperatures entailing their deterioration. In order to preserve the optimal conditions ensuring the good operation of the motor, it is imperative to well understand and control the thermal behavior of these motors. Heating problems into such machines remain alarming in spite of numerous progresses made for their design. In order to avoid these warmings, the cooling systems allowing dissipation of the heat flux to the ambient environment have to be taken into account in the optimized design of such machines. The synchronous motors operation is based on the existence of a rotating magnetic field which can be obtained by the circulation of a controlled current into stator winding. The main part of the electric power is converted into mechanical power, but the other part entails a warm up of the machine and constitutes the losses to be evacuated. To predict the lifetime of an electric motor and to improve its efficiency, it is necessary to carefully investigate its thermal design in order to determine the best cooling solutions. Keeping this aim in mind, we present an experimental technique allowing identification of the convective heat transfer coefficient inside a rotating cylinder with an axial airflow. This empty cylinder models the hollow rotor of the studied motor.

\section{Experimental setup}

Aiming at identify the convective heat transfer coefficient in an empty rotating cylinder with an inner axial airflow, a specific experimental setup was design. The infrared thermography lets obtain the temperature on the outer face of the heated cylinder. The heat equation in the cylinder is solved with three different ways letting obtain the inner convective heat transfer coefficient. This resolution also uses boundary and initial conditions imposed by experiments. 


\subsection{Experimental setup description}

Figure 1 presents the experimental setup. The rotating part is composed of three cylinders made of steel and separated by an insulation made of vetronite epoxy (VT) whose conductivity $\lambda_{V T}$ is $0.3 \mathrm{~W} / \mathrm{mK}$. These cylinders are concentric and reamed together to obtain a perfect interior surface quality. The $198 \mathrm{~mm}$ length central cylinder corresponds to the studied area. The internal and external diameters of the studied cylinders are respectively 393 and $403 \mathrm{~mm}$. The two $330 \mathrm{~mm}$ length cylinders surrounding the central cylinder are used to avoid the too disturbed phenomena at the inlet and the outlet, the insulation in VT being used to minimize the thermal losses of the studied zone towards the two cylinders of connection. The external face of the studied zone is heated with two fixed infrared transmitters located above and below the rotating part and connected to a power regulator. The power supply to the heat transmitters can be regulated manually between 0 and $4 \mathrm{~kW}$. An electric motor associated to a variable speed transmission drives the cylinder up to $1000 \mathrm{rpm}$. The rotating part is connected to the static part with two ball bearings assembled in ball self-aligning bearing. The static part is composed by a centrifugal ventilator connected to the revolving part with a $1.3 \mathrm{~m}$ length pipe on which a diaphragm is placed. The ventilator imposes an air flow in the test bench from 0 to about $530 \mathrm{~m}^{3} / \mathrm{h}$. Upstream and downstream the diaphragm, two pressure tappings are placed and let know the air flow rate in the test bench. This diaphragm is calibrated and the law obtained is in good agreement with Idel'cik [1]. The flow rate is determined with a relative uncertainty remaining lower than $6 \%$. The airflow provides by the ventilator to the revolving part impacts on a flask tapped with 4 holes of $50 \mathrm{~mm}$ of diameter equally distributed. The impact zone is in a small plenum chamber. The air from the ventilator enters into the rotating part via the plenum chamber, flows through the first cylinder used to homogenize the velocity profiles, then it flows through the studied area, and finally through the last cylinder before flowing by the outlet flange which is identical to the inlet one.

\subsection{Heat flux measurement and heating power estimation}

A regulator connected to the infrared lamps lets control the heat power transmitted to the cylinder. For each imposed power step, the heat flux received by the cylinder is identified versus the $\alpha$ angle (versus a horizontal line) using the radiative heat flux sensors noted $\mathrm{CF}_{\mathrm{i}}$ on fig. 2. These sensors are placed on the external surface of the zone studied and equally distributed in the axial direction (cf. Fig. 2-a). These square radiative heat flux sensors are sensitive neither to the conduction nor to the convection phenomena. They are $10 \mathrm{~mm}$ wide and $300 \mu \mathrm{m}$ thick. Their response time is about $100 \mathrm{~ms}$ and they have a linear sensitivity to the heat flux of about $0.5 \mathrm{mV} /\left(\mathrm{W} / \mathrm{m}^{2}\right)$. Relative uncertainty on the heat flux density $\varphi$ depends directly on the voltage measured since, if $s$ is the sensitivity of the sensor, $\varphi$ $=\mathrm{U} / \mathrm{s}$ and thus $(\Delta \varphi) / \varphi=(\Delta \mathrm{U}) / \mathrm{U} \approx 0.5 \%$. These sensors carry out a radiative heat balance on the irradiated surface. To know the heat flux density supplied by the infrared lamps $\varphi_{0}$, it will be thus necessary to add to the heat flux density measured with the sensors the part of heat flux emitted by the surface towards the surrounding $\left(=\varepsilon \sigma\left(T_{p}^{4}-T_{\infty}^{4}\right)\right)$. The integration of the heat flux density with $z$ and $\alpha$ determines the average heat flux density received by the cylinder since:

$$
\varphi_{0}=\frac{1}{S} \int_{S} \varphi d S=\frac{1}{2 \pi r_{e} L} \iint \varphi(z, \alpha) r_{e} d z d \alpha
$$


For example, in nominal operation the mean heat flux density received by the cylinder and generated by the infrared lamps is $2745 \pm 15 \mathrm{~W} / \mathrm{m}^{2}$.

\subsection{Temperature Measurement}

The surface temperature is obtained using an infrared camera placed in front of the area under investigation. It is a short wavelength infrared camera $(2-5.4 \mu \mathrm{m})$ equipped with $20 \times 12.5^{\circ}$ lens. It was used with a 20 hertz image acquisition frequency and a $204 \times 128$ pixel image definition. Its thermal resolution is $0.1 \%$ at $30{ }^{\circ} \mathrm{C}$. This camera returns a signal $\mathrm{I}(\mathrm{T})$ for a black body surface at the temperature $\mathrm{T}$ observed through a transparent environment. During measurement, the camera returns a digital signal originating from an elementary cylinder surface (see Fig. 3). In reality, due to the partial transmission through the surrounding air, the signal received by the camera is attenuated. In addition, this signal also takes into account environment radiation which reflects itself onto the cylinder. In order to improve the part of radiative heat flux emitted by the cylinder, the latter is painted black in order to increase its emissivity. The black painted surface emissivity, determined by calibration, is then $0.93 \pm 0.02$. A second calibration lets to connect, in a real situation, the thermal level I to the real temperature of the cylinder external surface. Absolute uncertainty on the temperature measurement with the camera remains lower than 0.1 $\mathrm{K}$ for the measurement range. The ambient air temperature, taken as a temperature reference to evaluate the heat transfer coefficient is measured using a type $\mathrm{K}$ thermocouple. The diameter of this thermocouple is $0.3 \mathrm{~mm}$ and its precision is $\pm 1 \mathrm{~K}$.

\section{Identification models of the internal convective coefficient}

Figure 4 presents a scheme of the studied problem. The rotating cylinder is heated on its external face by a radiative heat flux whereas its internal face is cooled down by an airflow whose speed $U_{\infty}$ and temperature $T_{\infty}$ are uniform. Initially the cylinder temperature is also assumed to be uniform. The test area is insulated from the other parts of the cylinder to promote a radial heat transfer and to significantly limit the axial and ortho-radial heat transfers. In this case the temperature field into the cylinder is supposed to be unidimensional and is denoted by $T(x, t)$. The heat transfer between the air and the inner and outer surfaces is characterized by the heat transfer coefficients $h_{i}$ and $h_{e}$. On the external surface of the cylinder, the heat transfer coefficient $h_{e}=h_{e}{ }^{c v}+h_{e}{ }^{r}$ is defined using the convective and radiative heat transfer coefficients. All thermo-physical properties $\rho, c$ and $\lambda$ of the cylinder are considered as constant. Taking into account the relative thickness of the cylinder when compared to its diameter $(e / D=0.0127)$ and defining $\theta(x, t)=T(x, t)-T_{\infty}$, the temperature evolution into the cylinder is then governed by:

$$
\begin{aligned}
& \frac{1}{\mathrm{a}} \frac{\partial \theta(\mathrm{x}, \mathrm{t})}{\partial \mathrm{t}}=\frac{\partial^{2} \theta(\mathrm{x}, \mathrm{t})}{\partial \mathrm{x}^{2}} \\
& \left.\frac{\partial \theta(\mathrm{x}, \mathrm{t})}{\partial \mathrm{x}}\right|_{\mathrm{x}=0}=\mathrm{H}_{\mathrm{e}} \theta(0, \mathrm{t})-\frac{\varphi_{0}}{\lambda},\left.\quad \frac{\partial \theta(\mathrm{x}, \mathrm{t})}{\partial \mathrm{x}}\right|_{\mathrm{x}=\mathrm{e}}=-\mathrm{H}_{\mathrm{i}} \theta(\mathrm{e}, \mathrm{t}), \quad \theta(\mathrm{x}, 0)=\theta_{\infty}
\end{aligned}
$$

Where $\mathrm{H}=\mathrm{h} / \lambda$ is the ratio between the convective coefficient and the thermal conductivity. The heat transfer equation and the boundary conditions of the problem define a system of differential equations where unknown quantities are the temperature and the internal convective coefficient $h_{i}$. The experimental setup lets determine the temperature evolution of external surface of the cylinder versus time and the heat flux density $\varphi_{0}$. The external convective coefficient $h_{e}$ is evaluated using 
data from literature [2-11]. Then an identification method letting identify the internal convective coefficient have to be developed. Three methods are proposed in this work: thin wall assumption model, inverse method, and analytical resolution of the heat transfer equation.

\subsection{Thin wall assumption model}

Considering the limited thickness of the wall $(5 \mathrm{~mm})$ and the thermal conductivity of the cylinder $\left(\lambda_{\text {cyl }}=43 \mathrm{~W} / \mathrm{mK}\right)$, the cylinder can be considered at every moment and for certain tests isotherm. With this assumption, the conservation of the energy equation within the cylinder follows the law of the thin bodies and the evolution of $h_{i}$ versus time can be obtained:

$$
\mathrm{h}_{\mathrm{i}}=\frac{\mathrm{S}_{\mathrm{e}} \varphi_{0}-\mathrm{mc} \frac{\mathrm{d} \theta}{\mathrm{dt}}}{\mathrm{S}_{\mathrm{i}} \theta}-\mathrm{h}_{\mathrm{e}} \frac{\mathrm{S}_{\mathrm{e}}}{\mathrm{S}_{\mathrm{i}}}
$$

In this equation, $d \theta / d t$ is estimated using the smoothed experimental temperature profile, $\varphi_{0}$ is measured as described in part 2.2, $\mathrm{h}_{\mathrm{e}}=\mathrm{h}_{\mathrm{e}}{ }^{\mathrm{cv}}+\mathrm{h}_{\mathrm{e}}{ }^{\mathrm{r}}$ where $\mathrm{h}_{\mathrm{e}}^{\mathrm{cv}}$ is obtained using the correlation from literature [2-11] and $h_{e}{ }^{r}$ using a linearization of the radiative heat flux, i.e. $h_{\mathrm{e}}^{\mathrm{r}}=\varepsilon \sigma\left(\mathrm{T}_{\mathrm{p}}^{2}+\mathrm{T}_{\infty}^{2}\right)\left(\mathrm{T}_{\mathrm{p}}+\mathrm{T}_{\infty}\right)$. In a steady state, the relative uncertainty on $\mathrm{h}_{\mathrm{i}}$ obtained with this method and our experimental conditions can be determined and remain lower than $6.4 \%$.

\subsection{Inverse model}

The finite differences are used to solve Eq. (2). The calculation domain is discretized into a node network where the temperature is calculated. The calculation of the inner convective heat transfer coefficient is achieved in three steps. The temperature is firstly calculated at the point $i=2$ using a heat balance in the cell between the point of external surface $i=1$ and the first inner point $i=2$ (cf. Fig. 5). The measurement point $i=1$ has two known conditions: its temperature resulting from infrared thermography and the heat flux. In a second step the temperatures at the nodes $i=3$ to $i=\mid$ are determined using the discretized heat equation. The last step consists in calculating the convective heat transfer coefficient on the inner surface of the cylinder using the temperature field calculated and the inner surface heat flux balance. For this model, several discretization schemes were used but only the Euler scheme is developed thereafter. The Euler's scheme uses an implicit formulation of the heat balance, thus:

$$
\begin{array}{lll}
\rho c \frac{\theta_{1}^{\mathrm{n}+1}-\theta_{1}^{\mathrm{n}}}{\Delta \mathrm{t}}=\frac{\varphi_{1+1 / 2}^{\mathrm{n}+1}-\varphi_{1}^{\mathrm{n}+1}}{\Delta \mathrm{x} / 2} & \text { for } \mathrm{i}=1 \\
\rho \mathrm{c} \frac{\theta_{\mathrm{i}}^{\mathrm{n}+1}-\theta_{\mathrm{i}}^{\mathrm{n}}}{\Delta \mathrm{t}}=\frac{\varphi_{\mathrm{i}+1 / 2}^{\mathrm{n}+1}-\varphi_{\mathrm{i}-1 / 2}^{\mathrm{n}+1}}{\Delta \mathrm{x}} & \text { for } 1<\mathrm{i}<\mathrm{I} \\
\rho \mathrm{c} \frac{\theta_{I}^{\mathrm{n}+1}-\theta_{I}^{\mathrm{n}}}{\Delta \mathrm{t}}=\frac{\varphi_{I}^{\mathrm{n}+1}-\varphi_{I-1 / 2}^{\mathrm{n}+1}}{\Delta \mathrm{x} / 2} & \text { for } \mathrm{i}=\mathrm{I}
\end{array}
$$

The heat flux densities can be formulated like below: 


$$
\begin{array}{lll}
\varphi_{1+1 / 2}^{n+1}=\lambda \frac{\theta_{1}^{n+1}-\theta_{2}^{n+1}}{\Delta x} & \varphi_{1}^{n+1}=\varphi_{0}-h_{c} \theta_{1}^{n+1} & \varphi_{i+1 / 2}^{n+1}=\lambda \frac{\theta_{i}^{n+1}-\theta_{i+1}^{n+1}}{\Delta x} \\
\varphi_{i-1 / 2}^{n+1}=\lambda \frac{\theta_{i-1}^{n+1}-\theta_{i}^{n+1}}{\Delta x} & \varphi_{1}^{n+1}=h_{i} \theta_{1}^{n+1} & \varphi_{1-1 / 2}^{n+1}=\lambda \frac{\theta_{I-1}^{n+1}-\theta_{1}^{n+1}}{\Delta x}
\end{array}
$$

And then, we obtain:

$$
\begin{aligned}
& \theta_{2}^{n+1}=\left[\frac{\Delta \mathrm{xh}_{\mathrm{e}}}{\lambda}-\frac{\chi}{2}+1\right] \theta_{1}^{\mathrm{n}+1}+\frac{\chi}{2} \theta_{1}^{\mathrm{n}}-\frac{\Delta \mathrm{x} \varphi_{0}}{\lambda} \\
& \theta_{\mathrm{i}+1}^{\mathrm{n}+1}=(2-\chi) \theta_{i}^{\mathrm{n}+1}-\theta_{\mathrm{i}-1}^{\mathrm{n}+1}+\chi \theta_{i}^{\mathrm{n}} \\
& \mathrm{h}_{\mathrm{i}}=\frac{\rho \mathrm{c} \Delta \mathrm{x}}{2 \Delta \mathrm{t}} \frac{\theta_{1}^{\mathrm{n}+1}-\theta_{1}^{\mathrm{n}}}{\theta_{1}^{\mathrm{n}+1}}+\frac{\lambda}{\Delta \mathrm{x}} \frac{\theta_{\mathrm{l}-1}^{\mathrm{n}+1}-\theta_{1}^{\mathrm{n}+1}}{\theta_{1}^{n+1}}
\end{aligned}
$$

With $\chi=\frac{(\Delta \mathrm{x})^{2}}{\mathrm{a} \Delta \mathrm{t}}, \mathrm{x}_{1}=0$ and $\mathrm{x}_{\mathrm{l}}=\mathrm{e}$. The resolution of this system requires the knowledge of $\theta_{1}$ provided at every moment by the infrared camera. It also requires the knowledge of $\varphi_{0}$ obtained using the heat flux sensors as described in part 2.2. The convective coefficient on the external face $\left(\mathrm{h}_{\mathrm{e}}^{\mathrm{cv}}\right)$ is determined using the correlation of the literature [2-11] and $h_{e}^{r}=\varepsilon \sigma\left(T_{p}^{2}+T_{\infty}^{2}\right)\left(T_{p}+T_{\infty}\right)$. In a steady state, the relative uncertainty on $h_{i}$ obtained with this method and with our experimental conditions remains lower than $7.4 \%$.

\subsection{Analytical model: heat equation resolution}

The development of the theoretical model is performed using an unidirectional modelling of the cylinder thermal behaviour. In addition, the cylinder is assumed to be a flat plate. The heat equation (2) is not homogeneous due to the boundary conditions at $x=0$. However, its resolution is possible by splitting it into two subsystems and defining the temperature $\theta$ such as $\theta(x, t)=\theta_{A}(x, t)+\theta_{B}(x, t)$. In this last expression, $\theta_{\mathrm{A}}(\mathrm{x}, \mathrm{t})$ stands for the solution of the non stationary homogeneous system, whereas $\theta_{B}(x)$ is the solution of the non-homogeneous stationary system.

$\underline{\text { non stationary homogeneous subsystem stationary subsystem }}$

$$
\begin{array}{lll}
\frac{1}{\mathrm{a}} \frac{\partial \theta_{\mathrm{A}}(\mathrm{x}, \mathrm{t})}{\partial \mathrm{t}}=\frac{\partial^{2} \theta_{\mathrm{A}}(\mathrm{x}, \mathrm{t})}{\partial \mathrm{x}^{2}} & \frac{\partial^{2} \theta_{\mathrm{B}}(\mathrm{x})}{\partial \mathrm{x}^{2}}=0 \\
\left.\frac{\partial \theta_{\mathrm{A}}(\mathrm{x}, \mathrm{t})}{\partial \mathrm{x}}\right|_{\mathrm{x}=0}=\mathrm{H}_{\mathrm{c}} \theta_{\mathrm{A}}(0, \mathrm{t}) & (7) & \left.\frac{\partial \theta_{\mathrm{B}}(\mathrm{x})}{\partial \mathrm{x}}\right|_{\mathrm{x}=0}=\mathrm{H}_{\mathrm{e}} \theta_{\mathrm{B}}(0)-\frac{\varphi_{0}}{\lambda} \\
\left.\frac{\partial \theta_{\mathrm{A}}(\mathrm{x}, \mathrm{t})}{\partial \mathrm{x}}\right|_{\mathrm{x}=\mathrm{e}}=-\mathrm{H}_{\mathrm{i}} \theta_{\mathrm{A}}(\mathrm{e}, \mathrm{t}) & \left.\frac{\partial \theta_{\mathrm{B}}(\mathrm{x})}{\partial \mathrm{x}}\right|_{\mathrm{x}=\mathrm{e}}=-\mathrm{H}_{\mathrm{i}} \theta_{\mathrm{B}}(\mathrm{e})
\end{array}
$$

$\theta_{\mathrm{A}}(\mathrm{x}, 0)=-\theta_{\mathrm{B}}(\mathrm{x})$

The resolution of the stationary subsystem (8) provides: 


$$
\left.\left.\theta_{\mathrm{B}}(\mathrm{x})=-\frac{\varphi_{0}}{\lambda\left[1+\frac{\mathrm{H}_{\mathrm{e}}}{\mathrm{H}_{\mathrm{i}}}\left(1+\mathrm{H}_{\mathrm{i}} \mathrm{e}\right)\right]}\right] \mathrm{x}-\frac{\left(1+\mathrm{H}_{\mathrm{i}} \mathrm{e}\right)}{\mathrm{H}_{\mathrm{i}}}\right]
$$

The solution of the homogeneous non stationary subsystem (7) is obtained using the variable separation method. This solution appears as:

$$
\theta_{\mathrm{A}}(\mathrm{x}, \mathrm{t})=\mathrm{e}^{-\mathrm{a} \mathrm{k}^{2} \mathrm{t}}[\gamma \cos (\mathrm{kx})+\delta \sin (\mathrm{kx})]
$$

$\mathrm{k}, \gamma$ and $\delta$ have to satisfy the boundary conditions. The boundary conditions at $\mathrm{x}=0$ is $\mathrm{k} \delta=\mathrm{H}_{\mathrm{e}} \gamma \quad$ and at $\mathrm{x}=\mathrm{e}: \quad \mathrm{k}(-\gamma \sin (\mathrm{ke})+\delta \cos (\mathrm{ke}))=-\mathrm{H}_{\mathrm{i}}(\gamma \cos (\mathrm{ke})+\delta \sin (\mathrm{ke})) . \quad$ By combining both equations, the following transcendent equation is obtained:

$$
\tan (\mathrm{ke})\left[\mathrm{Bi}_{\mathrm{e}} \mathrm{Bi}_{\mathrm{i}}-(\mathrm{ke})^{2}\right]=-\mathrm{ke}\left(\mathrm{Bi}_{\mathrm{e}}+\mathrm{Bi}_{\mathrm{i}}\right)
$$

This characteristic equation admits an infinity of discrete solutions $k_{n}$. The roots of this equation depend on the values of the external and internal Biot numbers $\left(\mathrm{Bi}_{\mathrm{e}}=\mathrm{eH}_{\mathrm{e}}\right.$ and $\left.\mathrm{Bi}_{\mathrm{i}}=\mathrm{eH} \mathrm{H}_{\mathrm{i}}\right)$. The general solution of the system (7) is expressed as series:

$$
\theta_{A}(x, t)=\sum_{n=1}^{\infty} e^{-a k_{a}^{2} t}\left[\gamma_{n} \cos \left(k_{n} x\right)+\delta_{n} \sin \left(k_{n} x\right)\right]
$$

Constants $\gamma_{\mathrm{n}}$ and $\delta_{\mathrm{n}}$ must satisfy the initial condition:

$$
\theta_{A}(x, 0)=-\theta_{B}(x)=\sum_{n=1}^{\infty}\left[\gamma_{n} \cos \left(k_{n} x\right)+\delta_{n} \sin \left(k_{n} x\right)\right]
$$

Applying the Fourier series theory, we obtained:

$$
\begin{gathered}
\gamma_{\mathrm{n}}=\frac{2 \mathrm{k}_{\mathrm{n}} \psi}{\cos \left(\mathrm{k}_{\mathrm{n}} \mathrm{e}\right) \sin \left(\mathrm{k}_{\mathrm{n}} \mathrm{e}\right)+\mathrm{ek}_{\mathrm{n}}}\left[\frac{\mathrm{e}-\phi}{\mathrm{k}_{\mathrm{n}}} \sin \left(\mathrm{k}_{\mathrm{n}} \mathrm{e}\right)+\frac{1}{\mathrm{k}_{\mathrm{n}}^{2}} \cos \left(\mathrm{k}_{\mathrm{n}} \mathrm{e}\right)-\frac{1}{\mathrm{k}_{\mathrm{n}}^{2}}\right] \\
\delta_{\mathrm{n}}=\frac{2 \mathrm{k}_{\mathrm{n}} \psi}{\mathrm{ek}_{\mathrm{n}}-\cos \left(\mathrm{k}_{\mathrm{n}} \mathrm{e}\right) \sin \left(\mathrm{k}_{\mathrm{n}} \mathrm{e}\right)}\left[\frac{\phi-\mathrm{e}}{\mathrm{k}_{\mathrm{n}}} \cos \left(\mathrm{k}_{\mathrm{n}} \mathrm{e}\right)+\frac{1}{\mathrm{k}_{\mathrm{n}}^{2}} \sin \left(\mathrm{k}_{\mathrm{n}} \mathrm{e}\right)-\frac{\phi}{\mathrm{k}_{\mathrm{n}}}\right] \\
\text { With } \phi=\frac{\left(1+\mathrm{H}_{\mathrm{i}} \mathrm{e}\right)}{\mathrm{H}_{\mathrm{i}}} \text { and } \psi=\frac{\varphi_{0}}{\lambda\left[1+\mathrm{H}_{\mathrm{e}} \phi\right]} .
\end{gathered}
$$

Finally, the solution of the problem (2) is written:

$$
\left.\theta(x, t)=\sum_{n=1}^{\infty} e^{-a k^{2} t}\left[\gamma_{n} \cos \left(k_{n} x\right)+\delta_{n} \sin \left(k_{n} x\right)\right]-\frac{\varphi_{0}}{\lambda\left[1+\frac{H_{e}}{H_{i}}\left(1+H_{i} e\right)\right.}\right]\left[x-\frac{\left(1+H_{i} e\right)}{H_{i}}\right]
$$

And the temperature of external surface 


$$
\theta(0, \mathrm{t})=\sum_{\mathrm{n}=1}^{\infty} \gamma_{\mathrm{n}} \mathrm{e}^{-\mathrm{ak}_{\mathrm{e}}^{2} t}+\frac{\varphi_{0}\left(1+\mathrm{H}_{\mathrm{i}} \mathrm{e}\right)}{\lambda\left[\mathrm{H}_{\mathrm{i}}+\mathrm{H}_{\mathrm{e}}\left(1+\mathrm{H}_{\mathrm{i}} \mathrm{e}\right)\right]}
$$

From equation (17) $h_{i}$ cannot be explicitly extracted. However, the temporal evolution of hi is obtained by identifying the experimental thermogram of the external surface temperature of the rotating cylinder and equation (17) at every moment. The evolution of the internal convective coefficient with time is then obtained. In a steady state, the value of $h_{i}$ is obtained when t tends towards infinity in equation (17) in $x=0$ (external face), so the convective heat transfer coefficient can be explicitly deduced.

$$
\mathrm{h}_{\mathrm{i}}=\frac{\lambda \varphi_{0}-\lambda^{2} \mathrm{H}_{\mathrm{e}} \theta_{\text {max }}}{\lambda \theta_{\text {max }}\left(1+\mathrm{H}_{\mathrm{e}} \mathrm{e}\right)-\varphi_{0} \mathrm{e}}
$$

This relation giving $h_{i}$ in steady state, can be directly obtained using heat resistances. In addition, in steady state, the relative uncertainty on $h_{i}$ obtained with this method and for our experimental conditions remains lower than $7.4 \%$.

\section{Results and comparisons}

The tests were carried out with a cylinder rotational speed ranging from 4 to $880 \mathrm{rpm}\left(1.6 \times 10^{3} \leq \operatorname{Re}_{\mathrm{r}} \leq 4.7 \times 10^{5}\right)$ and a variable flow rate varying from 0 to 530 $\mathrm{m}^{3} / \mathrm{h}\left(0 \leq \operatorname{Re}_{\mathrm{a}} \leq 3 \times 10^{4}\right)$.

A typical evolution of the external surface temperature of the cylinder versus time is plotted on Fig. 6. This monotonous evolution increases and tends asymptotically towards the temperature of thermal balance. These curves are well fitted by an exponential law such as $\theta=\theta_{\text {max }}\left(1-\sum_{i=1}^{N} \eta_{i} e^{-t / \tau_{i}}\right)$ obtained numerically for each test. The comparison of the different methods (inverse technique, isothermal model and analytical model) is carried out for the test with the cylinder in rotation at $880 \mathrm{rpm}$, without any axial airflow and heated with a $2745 \mathrm{~W} / \mathrm{m}^{2}$ heat flux density. The convective coefficient on the external cylinder surface $h_{e}{ }^{c v}$ is evaluated using the Dropkin and Carmi correlation [5]. It directly gives $h_{e}{ }^{c v}=44 \mathrm{~W} / \mathrm{m}^{2} \mathrm{~K}$. For the Euler model, the wall of the cylinder is discretized with 11 nodes equally spaced of 0.5 millimeter in the thickness direction. A finer mesh does not significantly change the values of $h_{\mathrm{i}}$. The time steps adopted for the time discretization is 60 seconds. This time step is chosen equal to the acquisition frequency of the external surface temperatures. The comparison of the results obtained (in terms of inner heat transfert coefficients) is presented on graph 7 . It is noted that the three curves relating to the models have almost the same trends. Whatever the identification method used, the initial value of the convective coefficient inside the cylinder is high. This value then gradually decreases and tends towards a limit value identical for all models for large times. These results also show a good agreement between the different models for $t$ larger than $480 \mathrm{~s}$ since for these times, the average relative error remains lower than $8 \%$. However for initial calculation steps $(t<480 \mathrm{~s})$ significant differences are to be noted. This can be explained, in the Euler model by the important time step (60 s) which alters the temporal derivative calculation whenever these derivatives strongly change and thus at the initial moments. For the isothermal model, the source of error can come from the isothermal assumption which is not true at the beginning. However the isothermal model gives excellent results for important times and can be 
quickly implemented. For the analytical model, $h_{i}$ is assumed to be constant for equations resolution, this assumption can entail inaccuracies at the initial instants. To calculate the convective coefficient in a steady state, the equilibrium temperature is averaged over the last moments (i.e. the last $600 \mathrm{~s}$ ). Its variation during this time is about $0.07 \mathrm{~K}$ and without significant consequence over the determination of $\mathrm{h}_{\mathrm{i}}$. These identification methods were also compared for low rotational speeds $(4 \mathrm{rpm})$ and results obtained (Fig. 8) are of the same magnitude order than those obtain for a static pipe with an airflow showing the suitability of the models proposed in this work. On figure 9 for low rotational speeds, the usual results of a static pipe are found again: heat transfer increases with the axial air flow. In addition, the axial flow is less influenced for the high rotational speed and the convective heat transfer is governed by the rotation.

\section{Conclusion}

This article shows how Infrared thermography can be used to identify convective heat transfer coefficient inside a heated empty rotating cylinder with an inner axial airflow. Several identification models were developed and compared in order to determine their relevance to evaluate the convective coefficient. They are all based on the knowledge of the external cylinder surface temperature obtained in experiments using infrared thermography. The investigations point out the time evolution of the convective coefficient on the internal face of the cylinder. The convective exchanges on the internal wall of the cylinder depend on the rotation and the axial air flow.

\section{REFERENCES}

[1] I.E. Idel'cik, Mémento des pertes de charges, Collection de la direction des études et recherches d'Électricité de France. Éditions Eyrolles, Paris, (1969).

[2] R.E.M. Morales, A. Balparda, A. Silveira-Neto, Large-eddy simulation of the combined convection around a heated rotating cylinder, Int. J. Heat Mass Tran. 42 (1999) 941-949.

[3] I.T. Anderson, O.A. Saunders, Convection from an isolated heated horizontal cylinder rotating about its axis, Proc. Roy. Soc. A., vol. 217, pp. 555, (1953).

[4] G.A. Etemad, Free convection heat transfer from a rotating cylinder to ambient air, with interferometric study of flow, Trans. ASME 77 (1955) 1283.

[5] D. Dropkin, A. Carmi, Natural convection heat transfer from a horizontal cylinder rotating in air, Trans. ASME, (1956) 741-749.

[6] W.M. Kays, I.S. Bjorklund, Heat transfer from a rotating cylinder with and without cross flow, Trans. ASME paper N56-a-71, (1956).

[7] B.A/K Abu-Hijleh, W.N. Heilen, Correlation for laminar mixed convection from a rotating cylinder, Int Comm. Heat Mass Transfer. 25 (6) (1998) 875-884.

[8] K.M. Becker, Measurements of convective heat transfer from a horizontal cylinder rotating in a tank of water, Int. J. Heat Mass Tran. 6 (1963) 1053-1062.

[9] A.A. Kendoush, An approximate solution of the convective heat transfer from an isothermal rotating cylinder, Int. J. Heat Mass Tran. 17 (1996) 439-441.

[10] B. Özerdem, Measurement of convective heat transfer coefficient for a horizontal cylinder rotating in quiescent air, Int. Comm. Heat Mass Transfer. 27 (3) (2000) 389-395.

[11] R. Shimada, T. Ohkubo, T. Kobayashi, S. Kumagai, Heat transfer from a rotating cylinder with and without cross flow, Heat transfer - Japanese research. 21 (1992) 109-122. 


\section{FIGURES}

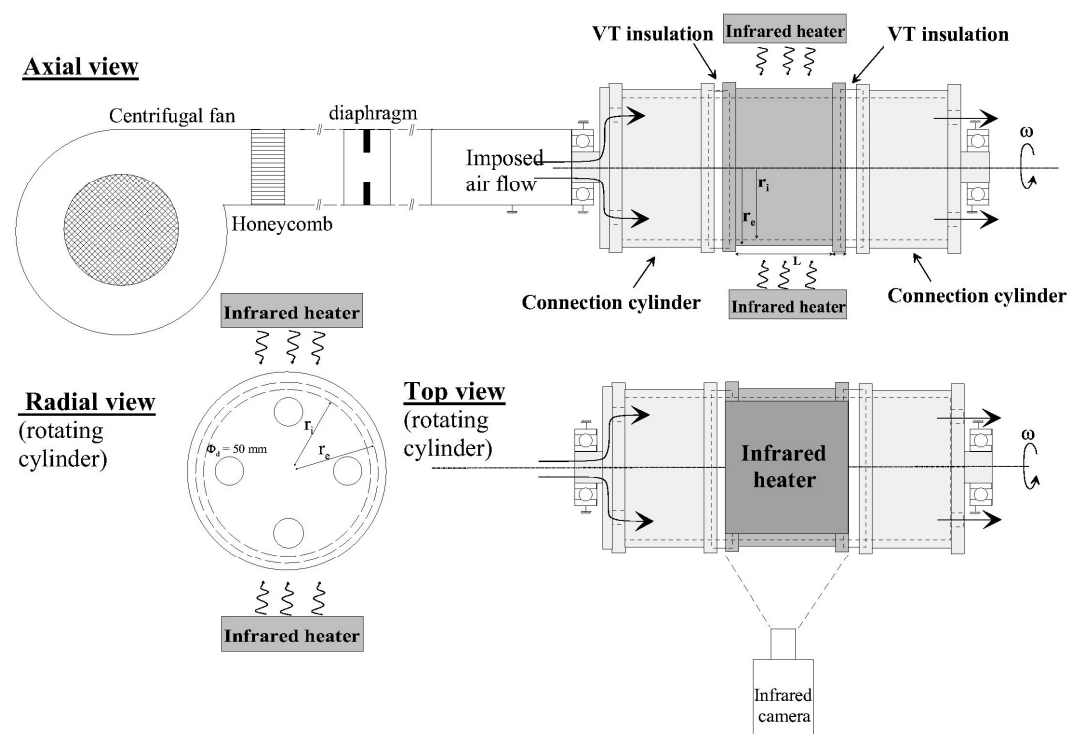

Fig. 1. Scheme of the experimental setup

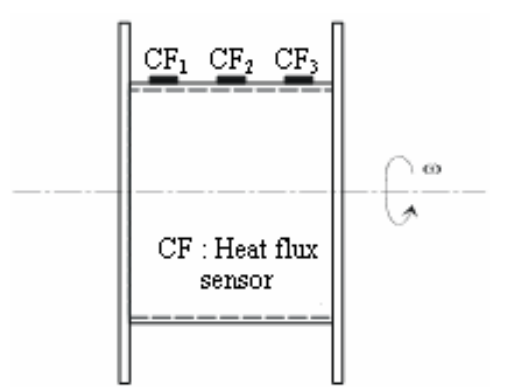

Fig. 2-a. Position of the heat flux sensor (axial view)

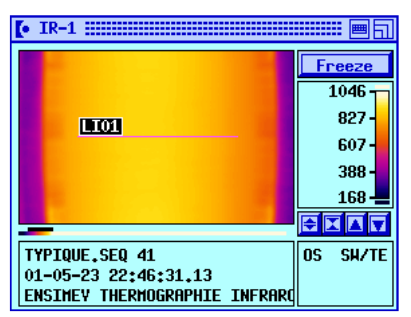

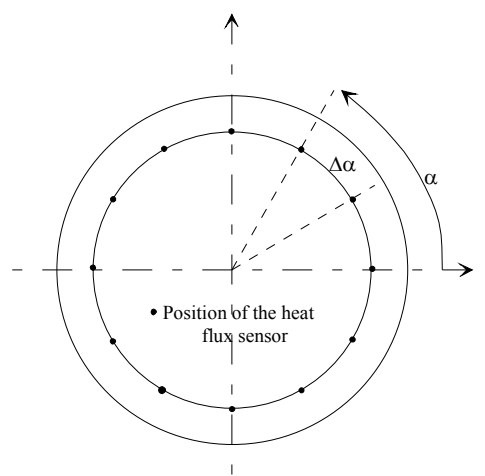

Fig. 2-b. Position of the heat flux sensor (radial view)

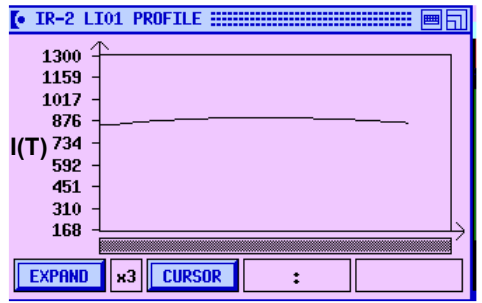

Fig. 3. Example of profile obtained with the infrared camera 


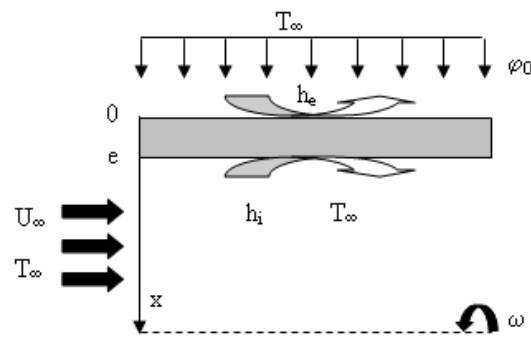

Fig. 4. Scheme of the studied problem

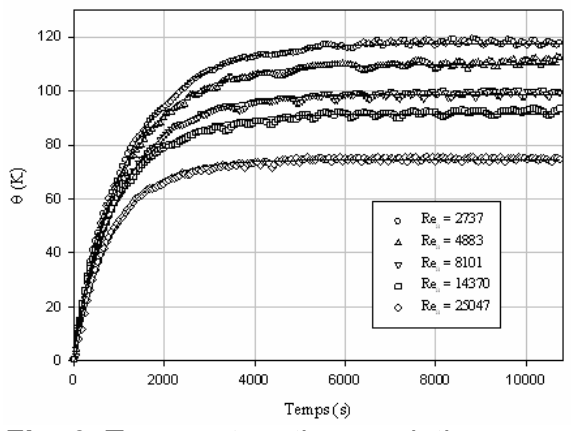

Fig. 6. Temperature time evolution on the cylinder outer surface with an axial air flow

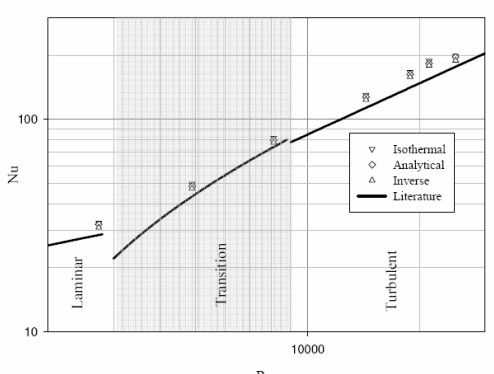

Fig. 8. Evolution of the inner Nusselt number with axial Reynolds number

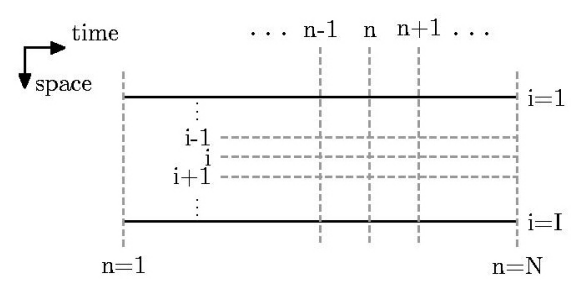

Fig. 5. Spatial and time discretization scheme

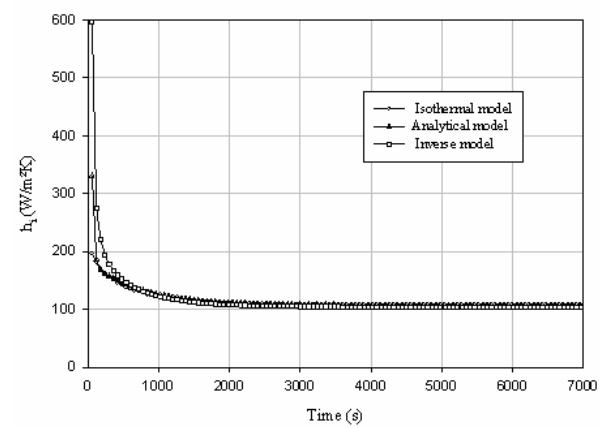

Fig. 7. Evolution of the heat transfer coefficient with time for the different models $\left(\operatorname{Re}_{\mathrm{r}}=458360\right.$ and $\left.\mathrm{Re}_{\mathrm{a}}=0\right)$

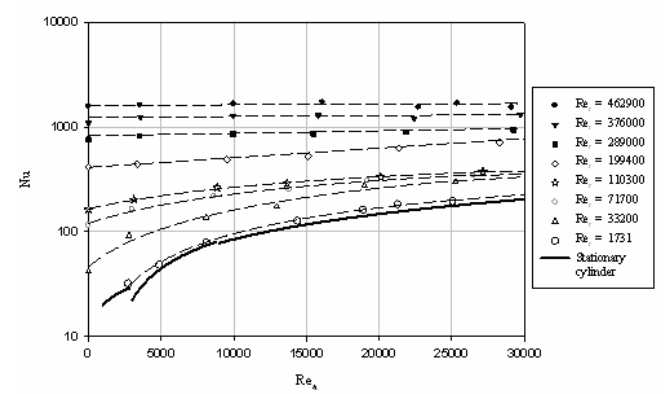

Fig. 9 Evolution of the Nusselt number with $\mathrm{Re}_{\mathrm{a}}$ for different rotational speeds 